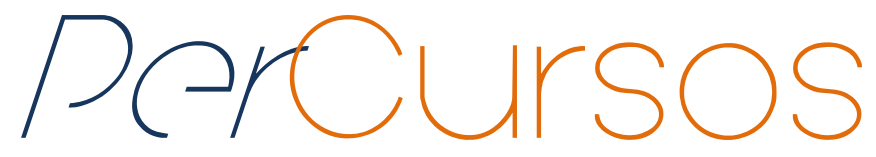

\title{
Experiências da prática docente na educação comunitária com jovens e adultos dentro do Projeto Integrar, em Florianópolis/SC
}

\begin{abstract}
Resumo
Esse artigo é parte da pesquisa de mestrado, que vem sendo desenvolvida no Programa de Pós-Graduação em Geografia da UFSC (Universidade Federal de Santa Catarina), na linha de pesquisa Geografia em Processos Educativos. Atualmente, encontra-se em fase de coleta de dados, na qual está se realizando um diagnóstico dos conhecimentos prévios dos estudantes ingressantes no Projeto Integrar ${ }^{1}$ em 2014/2015 (260 estudantes), bem como, levantamento e revisão do referencial bibliográfico. Objetiva-se socializar uma experiência vivida no movimento de educação comunitária "Projeto de Educação Comunitária Integrar" da prática docente dos educadores, principalmente na área de geografia, para o público da EJA (Educação de Jovens e Adultos). Compreende-se que a partir da realidade do cotidiano dos trabalhadores estudantes, os conteúdos tornam-se mais significativos para o processo de ensino-aprendizagem do estudante da EJA. Para isso, a formação docente tem um caráter importante, a fim que de os educadores possam criar estratégias metodológicas para a aprendizagem dos jovens e adultos. Portanto, conseguir o caráter emancipatório que a educação popular almeja.
\end{abstract}

Palavras-chave: Educação de jovens e adultos; Geografia - estudo e ensino; Professores de geografia - formação; Trabalhadores-estudantes.

\author{
Kleicer Cardoso Rocha \\ Mestrando em Geografia na \\ Universidade Federal de Santa \\ Catarina - UFSC. Professor de \\ Geografia no Colégio de \\ Aplicação da Universidade do \\ Vale do Itajaí - UNIVALI/SC e no \\ Projeto de Educação Comunitária \\ Integrar, em Florianópolis/SC. \\ Brasil \\ kleicer@gmail.com \\ Rosa Elisabete Militz
Wypyczynski Martins \\ Doutora em Geografia pela \\ Universidade Federal do Rio \\ Grande do Sul - UFRGS. \\ Professora da Univ. do Estado de \\ Santa Catarina - UDESC. \\ Brasil \\ rosamilitzgeo@gmail.com
}

\footnotetext{
${ }^{1}$ O Projeto de Educação Comunitária Integrar é um movimento de professores voluntários, que luta pela inserção de trabalhadores estudantes nas universidades públicas catarinenses através das políticas de ações afirmativas, construindo junto aos trabalhadores estudantes práticas de intervenção social a partir dos conhecimentos adquiridos na universidade seguindo, desta forma, quatro eixos: acesso, permanência, formação docente e intervenção social.
} 


\title{
Experiences of teaching practice in community education with young people and adults, within the Projeto Integrar, in Florianopolis/SC
}

\begin{abstract}
This article is part of the master's research, that has been developed in the Graduate Program in Geography at UFSC (Federal University of Santa Catarina), in the search line Geography in Educational Processes, and is in data collection phase, in which we are carrying out a diagnosis of previous knowledge of students entering the Project Integrar in 2014/2015 (260 students), and, survey and review of bibliographic references. Our objective in this article is to socialize a lived experience in the movement of community education Project Integrar the teaching practices of educators, especially in the geography for the public of EJA (Youth and Adult Education). We understand that from the reality of the daily lives of student workers, the contents become more significant for the process of teaching and learning students in the EJA. For this, the teacher training has an important character, so that educators can create methodological strategies for the learning of young people and adults. And with that, get the emancipatory character that popular education aims.
\end{abstract}

Keywords: Youth and adult education; Geography study and teaching; Geography teacher - training; Working students.

\section{Para citar este artigo:}

ROCHA, Kleicer Cardoso; MARTINS, Rosa Elisabete Militz Wypyczynski. Experiências da prática docente na educação comunitária com jovens e adultos dentro do Projeto Integrar, em Florianópolis/SC. Revista PerCursos, Florianópolis, v. 17, n.33, p. 117 -143, jan./abr. 2016.

\section{DOI: 10.5965/1984724617332016117}

http://dx.doi.org/10.5965/1984724617332016117 


\section{Introdução}

O Projeto Integrar é um movimento de professores lutadores da educação popular, o qual está em atividade há quatro anos, atuando com a educação comunitária, atendendo o público de trabalhadores estudantes. O perfil dos docentes que atuam neste projeto é de professores em processo de formação universitária, bem como de professores já graduados e pós-graduandos, todos ligados às atividades de pré-vestibular com fins de inserção de trabalhadores estudantes em situação de vulnerabilidade social nas universidades públicas catarinenses.

Os professores de Geografia do Projeto Integrar compõem uma equipe de 5 (cinco) membros; destes, 2 (dois) têm formação em licenciatura plena pela UDESC (Universidade do Estado de Santa Catarina), 1 (um) é bacharel em Geografia pela UFSC (Universidade Federal de Santa Catarina), dois (2) ainda estão em processo de formação em licenciatura pela UDESC e UFSC. Dos professores formados, 2 (dois) estão cursando mestrado pelo Programa de Pós-Graduação em Geografia da UFSC, e 1 (uma) está cursando doutorado pelo Programa de Pós-Graduação em Geografia da UFSC.

Este projeto faz parte do movimento brasileiro do debate das Políticas de Ações Afirmativas, o qual possibilita, por meio das políticas de cotas, a inserção de trabalhadores estudantes de escolas públicas, negros e indígenas nas universidades públicas - neste caso em particular, UFSC, UDESC e IFSC (Instituto Federal de Santa (atarina). A questão problematizadora abordada está relacionada com a prática docente do professor de geografia com estudantes da EJA (Educação de Jovens e Adultos), ou seja, busca-se saber como ocorre a formação inicial e continuada dos professores dentro dos movimentos sociais que trabalham com os conteúdos geográficos com os estudantes da EJA, na perspectiva da formação política. Também se busca compreender a formação continuada do professor dentro de um coletivo na educação popular com a EJA em Florianópolis.

Desta forma, pretende-se construir junto aos educandos uma formação crítica, despertando nos estudantes o exercício da cidadania, para que possam ter maior intervenção social e serem mais atuantes nos seus lugares de vivências, como o local de 
trabalho, a comunidade, os espaços escolares, e as universidades. Assim, foi organizada uma metodologia na qual o diálogo com os saberes prévios dos estudantes marca o ponto de partida dos conteúdos geográficos para a ampliação dos saberes dos trabalhadores estudantes.

Para o referencial teórico do campo do ensino de Geografia e da Educação, propondo um diálogo sobre a formação docente inicial e continuada em debate acerca do professor intelectual transformador, utilizou-se Giroux (1997). Explorou-se Contreras (2002), Morgado (2011) e Tardif (2011), no debate da profissionalização docente e o professor como formador de conhecimentos. Bem como Cavalcanti (2010) foi uma referência importante, por tratar da prática docente e das múltiplas formas do fazer pedagógico no ensino de geografia. Metodologicamente recorreu-se ao método quali-quantitativo por meio da observação participante e questionário semiestruturado para o levantamento dos dados para este estudo. A pesquisa se encontra em fase de coleta de dados qualitativos, na qual estamos realizando um diagnóstico dos conhecimentos prévios dos estudantes que ingressaram no Projeto Integrar em 2014/2015, bem como levantamento e revisão do referencial bibliográfico.

A referida pesquisa, em seu caráter qualitativo, privilegiou o recurso das entrevistas, já que, de acordo com a intenção do estudo, esse consiste no instrumento mais adequado para se chegar às informações coletadas sobre os trabalhadores estudantes do Projeto Integrar. A partir do questionário semiestruturado é possível desenhar esta proposta avaliando tanto o desenvolvimento do processo de ensinoaprendizagem, como a participação e envolvimento dos trabalhadores estudantes no projeto. Além disso, verifica-se a possibilidade de compor redes dentro das universidades como estratégias na permanência dos estudantes no percurso universitário, ampliando, assim, a atuação do Projeto Integrar nos territórios nas quais eles/alas atuam, bem como entender a bagagem de conhecimentos que os estudantes trazem da sua formação escolar e do mundo do trabalho.

Para atender os objetivos e o presente método, realizou-se um estudo de caso considerado adequado, pois privilegia uma análise minuciosa de um ambiente em particular. A observação de caráter participante será a opção metodológica de 
levantamento dos dados, em virtude da participação ativa junto ao projeto como um dos professores e idealizadores do Projeto Integrar. De acordo com Brandão, a pesquisa participante deve "partir da realidade concreta da vida cotidiana dos próprios participantes individuais ou coletivos do processo, em suas diferentes dimensões e interações" (BRANDÃO, 2006, p. 41).

\section{Contextualizando o Projeto de Educação Comunitária Integrar}

Dentro do contexto histórico da educação, o Projeto de Educação Comunitária Integrar atua na luta pela democratização do ensino no Brasil, atendendo ao público de EJA no atendimento da formação continuada daqueles trabalhadores estudantes que querem continuar seus estudos, buscando o ingresso na universidade, pois são trabalhadores que já conseguiram sua formação escolar e pararam de estudar, porém através do projeto comunitário gratuito e das oportunidades de acesso à universidade, estão voltando aos estudos. Entre esses estudantes, há muitos oriundos da Educação de Jovens e Adultos.

De acordo com Laffin os sujeitos da EJA são:

jovens, adultos e idosos, homens e mulheres, na sua maioria oriundos dos segmentos populares, que trazem uma história de vivências de desigualdades sociais perante o mundo e a escola. Alunos que precisam ser compreendidos como sujeitos socioculturais constituídos por percursos próprios de inserção no mundo. (LAFFIN, 2012, p. 223)

Atendem-se esses trabalhadores estudantes, negros, pobres, das escolas públicas e das periferias urbanas, pois considera-se este público como o mais marginalizado e que necessita de políticas públicas estruturantes com o intuito de eliminar uma dívida história do direito à escolaridade. Assim, atua-se na região da grande Florianópolis $/ \mathrm{SC}^{2}$ (com estudantes dos municípios de São José, Biguaçu, Palhoça e Governador (elso Ramos). 
Com isso, o Projeto Integrar vem desenvolvendo suas ações ligadas às Políticas de Ações Afirmativas do Governo Federal $^{3}$, as quais são aplicadas nas instituições públicas de Santa Catarina, como a UFSC, a UDESC e o IFSC, as chamadas "cotas" para estudantes de escolas públicas, étnico-raciais e indígenas. Segundo Furtado (2006), permitir que o aumento de oportunidades no ensino superior público se combine com maior democratização econômica e étnico-racial no acesso e permanência no ensino superior é uma tarefa da universidade pública.

Dentro dessas ações pensadas pela Universidade, o Projeto Integrar vem desenvolvendo projetos voltados ao acesso e à permanência dos estudantes da EJA nos bancos universitários, ações que ocorrem no modelo de cursos pré-vestibulares populares. Porém, com uma metodologia diferenciada de atuação, com a qual se busca ir além de conquistar o acesso à universidade; tem também como objetivo formar os estudantes para que possam ser cidadãos críticos e atuantes no percurso formativo universitário, e mais ainda na pós-formação, para que possam ter atuações nos seus respectivos lugares de vivências e dentro do Projeto Integrar.

Diante das desigualdades de acesso dos trabalhadores nas universidades públicas, com a preparação no Projeto Integrar, os estudantes têm maior possibilidades de conquistar o acesso, isso ligado às políticas de ações afirmativas. Desde a sua criação, em agosto de 2011 - portanto, em 2015, completando 4 (quatro) anos de projeto - já são mais de 150 trabalhadores estudantes nas universidades públicas catarinenses, nos mais diversos cursos universitários: engenharias, arquitetura, direito, geografia, história, pedagogia, ciências sociais, filosofia, sistemas da informação, geologia, agronomia, serviço social, matemática, para mencionar os estudantes que estão organizados na Gestão Estudantil Universitária Integrar (GESTUS ${ }^{4}$ ). O grupo de estudantes do Projeto

\footnotetext{
Amaro da Imperatriz, Biguaçu, Governador Celso Ramos, São José, Palhoça e Florianópolis.

${ }^{3}$ Políticas de Ações Afirmativas são medidas especiais de políticas públicas e/ou ações privadas de cunho temporário ou não. Tais medidas pressupõem uma reparação histórica de desigualdades e desvantagens acumuladas e vivenciadas por um grupo racial ou étnico, de modo que essas medidas aumentam e facilitam o acesso desses grupos, garantindo a igualdade de oportunidade. Disponível em: http://acoesafirmativas.ufsc.br/, acesso em 20 de junho de 2014.

${ }^{4}$ GESTUS- Gestão Estudantil Universitária Integrar é uma organização de estudantes do projeto que estão coletivamente lutando pela permanência nas universidades públicas, com ajuda mútua tanto financeira
} 
Integrar está lutando pela permanência na universidade, com apoio financeiro, pedagógico, através de reforços matemáticos, com oficinas de escrita, cursos de línguas e apoio inicial para as conquistas dos direitos como Restaurante Universitário, Moradia Estudantil, bolsas de estudos e formulação do Cadastro Socioeconômico.

Tem-se o entendimento de que, no processo histórico, a educação foi negada a uma grande parte da população brasileira, mas sabe-se que a educação é um campo de disputa, por isso, Freire (2005) fala que a educação é um fazer político, e tem-se o dever de saber para quem se está educando, contra quem está-se educando, e trabalhar com a EJA é escolher o campo de luta das causas dos trabalhadores. Como movimento social da educação, luta-se na Educação de Jovens e Adultos, buscando oportunizar através da luta coletiva, de professores e estudantes do Projeto Integrar, o acesso e a permanência dos trabalhadores estudantes, nas universidades públicas, na perspectiva de uma educação libertadora.

Para conseguir dialogar com as causas dos trabalhadores, a disciplina de geografia dentro do Projeto Integrar, busca trazer categorias de análises através dos seus conteúdos programáticos, a fim de que "a vida escolar [seja] contextualizada como arena repleta de contestação, luta e resistência [pois] a meta fundamental da educação é criar condições para que os estudantes se fortaleçam e se constituam como indivíduos políticos" (GIROUX, 1997, p. 203). O Projeto de Educação Comunitária Integrar visa transformar a realidade social por meio da educação dos trabalhadores estudantes, e tem como proposta a articulação em 4 (quatro) eixos:

$1^{\circ}$ eixo - Acesso à Universidade, proporcionar curso pré-vestibular gratuito extensivo de 8 meses e semiextensivo de 4 meses, voltados aos sujeitos de escola pública, negros e indígenas, em situação de vulnerabilidade social, que tenham o acesso através das políticas de ações afirmativas (cotas), nas universidades públicas de Santa Catarina;

$2^{\circ}$ eixo - Permanência na Universidade através da GESTUS (Gestão Estudantil Universitária Integrar), que proporciona o apoio aos trabalhadores estudantes durante seu percurso formativo na graduação,

como de apoio pedagógico, com reforços em escrita e cálculos. 
visando a permanência destes, evitando o baixo rendimento acadêmico e diminuindo a evasão;

$3^{\circ}$ eixo - Formação Docente, oportunizar a experiência da prática docente para o público da EJA, a fim de formar educadores em início de carreira, sensibilizados com a causa da educação dos trabalhadores.

$4^{\circ}$ eixo - Prática de Intervenção Social, através dos estudantes universitários e professores do Projeto Integrar, ligar os saberes acadêmicos com as necessidades e realidades sociais dos territórios dos nossos estudantes, transformando as realidades. Estamos desenvolvendo projeto de Horta Urbana no território da José Botieux, no Maciço do Morro da Cruz, ligando os saberes da estudante de agronomia e sociologia com o território da estudante de ciências sociais. (ROCHA, 2015, p. 5)

O Projeto Integrar busca envolver o trabalhador estudante com os princípios da educação popular e da cidadania em seu sentido mais profundo. O Projeto é formado por educadores totalmente voluntários e tem estrutura autônoma, sem vinculação com governos, partidos políticos ou autarquias. "Somos um projeto em constante transformação, que busca a cada dia se aproximar mais de suas próprias utopias, uma possibilidade de educação comunitária que reconhece e valoriza as diferenças, para fazer diferente" (INTEGRAR, 2014).

Apesar de todas as dificuldades inerentes a um projeto comunitário de educação, o Integrar segue sua história de luta e envolvimento social, dando cada vez mais sentido ao seu lema: “Educação feita com paixão”. Em 2014, iniciaram-se dois novos caminhos na educação, com a criação de hortas urbanas nos territórios do Maciço do Morro da Cruz, lugar de vivência dos nossos estudantes, promovendo a ponte entre as necessidades dos territórios e os conhecimentos adquiridos dos trabalhadores estudantes nas universidades cumprindo, desta forma, com a função social de um estudante universitário, dando um retorno aos territórios dos conhecimentos apreendidos nas universidades públicas. O segundo projeto está relacionado com a formação dos estudantes universitários na formulação de artigos científicos nos seus respectivos cursos, com a orientação dos professores da GESTUS, através de oficinas de escritas.

O presente artigo tem como foco o $3^{\circ}$ eixo do Projeto Integrar, o qual está relacionado com a formação continuada do professor para atender ao público da 
Educação de Jovens e Adultos, mais especificamente do professor de geografia, suas metodologias e práticas docentes a fim de fazer com que os estudantes possam se apropriar dos conhecimentos geográficos e, assim, fazer novas leituras de mundo a partir das categorias de análises apreendidas.

O Projeto de Educação Comunitária Integrar é um projeto desenvolvido em Florianópolis/SC, localizado na escola pública estadual IEE (Instituto Estadual de Educação), no centro da cidade - e, desta forma, de fácil acesso aos estudantes. Conta com a participação de aproximadamente 33 professores ativos em sala de aula, bem como cerca de 10 professores atuantes nos bastidores, com apoios burocráticos ao Projeto. Conta-se com professores formados e/ou em processos de formação em suas respectivas áreas de atuação. O Projeto trabalha com todas as disciplinas necessárias para a preparação dos estudantes para o concurso Vestibular (Geografia, História, Sociologia, Redação, Línguas - Portuguesa e Estrangeira: Inglês e Espanhol -, Literatura, Química, Física, Matemática e Biologia).

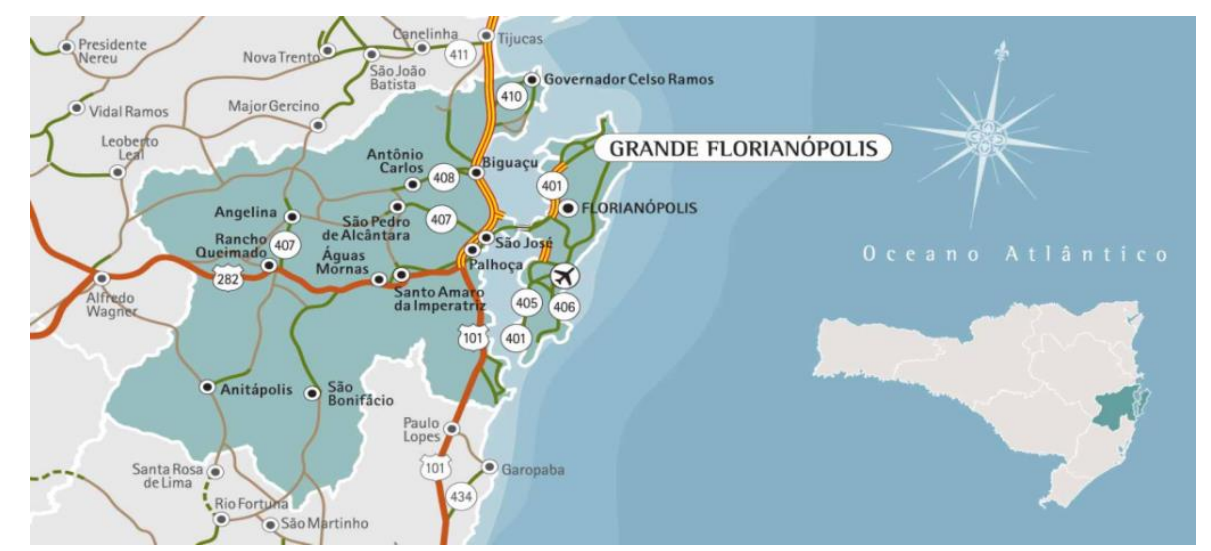

Figura 1 - Território de atuação do Projeto Integrar

Fonte: Disponível em: http://angulocursos.blogspot.com.br/2010/05/ilha-de-santa-catarina-e-grande.html, acesso em 20 de junho de 2014.

Conforme se observa na Figura 1, o espaço geográfico de atuação do Projeto Integrar abrange toda a Região Metropolitana de Florianópolis, composta por 13 municípios (Anitápolis, Rancho Queimado, São Bonifácio, Angelina, Antônio Carlos, Águas Mornas, São Pedro de Alcântara, Santo Amaro da Imperatriz, Biguaçu, Governador Celso Ramos, São José, Palhoça e Florianópolis). Segundo Henrique (2007, p. 48), o IBGE de 
2002 considera a Região Metropolitana como "uma área instituída por legislação estadual e constituída por agrupamentos de municípios limítrofes, com o objetivo de integrar a organização, o planejamento e a execução de funções públicas de interesse comum".

A delimitação e recorte espacial se referem a uma escala mesolocal, de acordo com a classificação de Souza (2013, p. 204), na qual equivale ao que chama-se "uma aglomeração de cidades de porte médio (uma metrópole ou aglomeração de porte metropolitano)". Neste contexto a atuação do Projeto Integrar na Região Metropolitana de Florianópolis, se insere na escala mesolocal. De acordo com Souza (2013), é nesse nível escalar que os movimentos sociais podem apresentar uma maior atuação participativa, ou seja:

os movimentos sociais emancipatórios aguerridos - que servem da ação direta e da luta institucional não partidária (participação em audiências públicas, pressões para influenciar a legislação etc.) para instituir novas relações de poder, forçar processos (re)distributivos e fomentar transformações sócio-espaciais em geral. (SOUZA, 2013, p. 206, grifo nosso)

Com o envolvimento dos professores intelectuais transformadores (GIROUX, 1997) e a luta coletiva dentro do Projeto Integrar, conseguiu-se envolver os estudantes para uma maior participação e, desta forma, avançar nas transformações das realidades dos trabalhadores estudantes.

\section{Educação de Jovens e Adultos - trabalhadores estudantes: um diagnóstico}

Os sujeitos desta pesquisa estão distribuídos dentro da escala mesolocal, mas na perspectiva da escala de análise (SOUZA, 2013), ou seja, lugar de moradia/vivência dos estudantes trabalhadores.Esses estudantes estão distribuídos nos municípios de Florianópolis, São José, Biguaçu, Palhoça e Governador Celso Ramos. São 125 estudantes que frequentaram o Projeto de Educação Comunitária Integrar no ano de $2014^{5}$, sendo a 
maior parte deles (82) do sexo feminino (66\%) e 43 do sexo masculino (34\%). As idades variam de 18 a 55 anos. De acordo com a situação étnico-racial, 65\% (81) dos estudantes se autodeclararam brancos. Os declarados negros e pardos, portanto dentro das políticas de cotas raciais, são $29 \%$ dos estudantes (36), sendo apenas 4 estudantes indígenas e 4 autodeclarados amarelos. Nesta perspectiva étnico-racial, ainda é preciso avançar mais.

Com relação à escolaridade, o Projeto busca estudantes com o perfil das Políticas de Ações Afirmativas, a qual prioriza aqueles com a formação no ensino básico público e, nessa questão, a maioria estudou em escolas públicas, 92 estudantes ou 74\%; já os estudantes de escola participar são apenas 6 (5\%). Tem-se também 21\% (27 estudantes) que estudaram em ambos os sistemas (escolas públicas e particulares, muitos com bolsas de estudos) e, portanto, segundo os critérios das políticas de cotas, estão fora do perfil.

Entende-se de suma importância, nesse diagnóstico, o conhecimento, por parte dos docentes, da origem escolar de nossos estudantes, pois sabemos o nível de aprendizagem nas escolas públicas nos dias de hoje. De acordo com IDEB 2011 - Índice de Desenvolvimento da Educação Básica para o ensino médio, a nota média nacional ficou em torno de 3,7 dentro das escolas públicas brasileiras. Em Santa Catarina, a média não foi muito diferente da média nacional, pois a nota média ficou em torno de 4,3. É importante salientar, que mesmo o IDEB sendo um avaliador quantitativo, é um demonstrativo de parte da realidade educacional brasileira. Assim, pensar em estratégias metodológicas que dialoguem com essa realidade, permite que os estudantes possam ampliar seus conceitos, buscando no processo de ensino-aprendizagem garantias de apropriação de novas categorias de análise do cotidiano dos estudantes.

Com relação à situação de trabalho, o perfil dos estudantes do Projeto Integrar em 2014 é composto por 83\% de trabalhadores estudantes, porcentagem que se subdivide em três categorias: aqueles com maior estabilidade, trabalhadores com carteira assinada (40\%) 50 estudantes; aqueles autônomos/informais ( $9 \%$ - 12 estudantes) e; aqueles que estão desempregados no momento das inscrições e do processo de seleção para o 
ingresso no Projeto Integrar, sendo que essa situação pode variar, pois os estudantes relataram que estão em busca de um trabalho - esses são cerca de $34 \%$ ou 42 estudantes. Complementando a situação do mundo do trabalho, $17 \%$ dos estudantes nunca trabalharam.

Desta realidade do mundo do trabalho, os referidos estudantes apresentam, em sua maioria ( $83 \%$ deles), uma renda de até 3 (três) salários-mínimos ( $R$ \$ 2.172,00), sendo 1 (um) salário-mínimo, em 2014, o equivalente a $\mathrm{R} \$ \mathbf{7 2 4 , 0 0 .}$ Tendo em vista o perfil socioeconômico dos estudantes do Projeto Integrar em 2014 dentro do processo de ensino-aprendizagem, caracteriza-se como um estudante trabalhador a pessoa com renda de até três salários-mínimos, que frequentou escola pública, é branca e do sexo feminino.

\section{Professores no Projeto Integrar: intelectuais transformadores na educação}

\section{popular}

Dentro da educação popular, é imprescindível o debate político no qual os professores são os responsáveis pelo movimento e construção de identidade de um movimento social, haja vista o papel formador do professor como agente social no processo de transformação social dos sujeitos (trabalhadores estudantes) e das múltiplas realidades apresentadas por eles. Conforme Giroux (1997, p. 161), o professor como intelectual transformador tem desempenhado um papel importante "na produção e legitimação de interesses políticos, econômicos e sociais variados através das pedagogias por eles endossadas e utilizadas".

Cabe, portanto, ao professor trazer o debate político, econômico e social das múltiplas realidades dos estudantes, pois o acesso aos bancos universitários vai além de uma preparação conteudista, pois no imaginário popular, trabalhadores estão fora de alcançar o acesso à universidade, o que torna esse movimento extremamente significativo na vida dos trabalhadores estudantes, rompendo assim com os paradigmas de que os eles não são capazes de entrar/estar nas universidades públicas. No entanto, com uma pedagogia voltada para a formação crítica, obteve-se uma mudança das 
relações sociais no seu ambiente de trabalho, na sua comunidade, na sua família, nos seus círculos de amizade, proporcionando uma nova visão de mundo e, assim, a possibilidade de criar formas novas de intervenção social.

Para isso, os professores estão em constantes movimentos de construção de uma identidade de trabalhadores estudantes, pois é "importante enfatizar que os professores devem assumir responsabilidade ativa pelo levantamento de questões sérias acerca do que ensinam, como devem ensinar e quais são as metas mais amplas pelas quais estão lutando" (GIROUX, 1997 p. 161). Para o Projeto Integrar, as aulas vão além da mera transmissão de conteúdos programáticos, "as aulas visam aguçar o espírito crítico, o debate saudável e a construção conjunta do conhecimento, pois é nisso que acreditamos" (INTEGRAR, 2014).

Assim, segundo Morgado, compreende-se “que o saber profissional do professor não possa restringir-se ao mero domínio de um conjunto de conhecimentos científicos relativos aos conteúdos curriculares [...] e metodológicos das ciências da educação" (2011, p. 797), pois o professor deve "ensinar como fazer com que os outros aprendam/apreendam o saber que se disponibiliza" (MORGADO, 2011, p. 797). Nesse processo de aprendizagem, os sujeitos ampliam seu grau de letramento, conseguindo ter outras visões de mundo e, desta forma, podem se posicionar e lutar a favor da ampliação dos seus direitos, principalmente no que diz respeito ao acesso e permanência na universidade pública.

Com isso, os professores do Projeto Integrar estão em um processo de construção de conhecimentos dialogando com os saberes prévios dos trabalhadores estudantes, buscando como professores intelectuais numa relação dialógica, a construção coletiva de conhecimento.

Ao realizar o diagnóstico inicial, a fim de conhecermos as trajetórias de vida e luta dos estudantes, buscou-se compreender o quanto de saberes empíricos esse estudante traz para a sala de aula. A partir destes saberes, pode-se identificar o quanto se avançou nas categorias de análises da realidade, a fim de que os estudantes possam ampliar suas 
visões de mundo, se apropriando de novas categorias e, com elas, transformar a sua realidade.

O primeiro grande processo de transformação é o acesso à universidade pública através das políticas de ações afirmativas, entendidas como um direito dos estudantes de escolas públicas, negros e indígenas de acessar aos cursos universitários. No entanto, no diagnóstico inicial, os estudantes apresentam certas dúvidas quanto a se inscreverem pelas políticas de cotas, devido à falta de entendimento e percepção em compreender as desigualdades criadas no acesso ao ensino superior em nosso país.

No processo de luta dos professores em sala de aula, com o objetivo de ampliar as visões de mundo dos estudantes se dá a partir das ideias e do planejamento coletivo, onde cada professor, por meio de sua prática pedagógica, no seu fazer reflexivo, com suas ferramentas metodológicas, cria as possibilidades para tal concretização.

Porém, como um grupo de professores, lutadores de uma causa em comum, têmse os mesmos objetivos como Projeto Integrar: proporcionar o acesso e a permanência dos trabalhadores estudantes nos bancos universitários, dos mais diversos cursos da UFSC, UDESC e IFSC, lutando contra as injustiças dentro dessas mesmas instituições em queestudantes cotistas são estigmatizados, principalmente nos cursos mais elitizados, como medicina, odontologia, arquitetura e as engenharias.

De acordo com Giroux (1997, p. 163) os professores intelectuais “devem trabalhar para criar as condições que dêem aos estudantes a oportunidade de tornarem-se cidadãos que tenham o conhecimento e a coragem para lutar [...]" contra a discriminação institucional em um primeiro momento.

Como um Projeto de Educação Comunitária composto por um grupo de 43 professores de todos os campos do conhecimento, propôs um conjunto de ações coletivas com as quais luta no intuito de inserir trabalhadores estudantes na universidade pública. Como frisa Morgado atualmente

[...] tem sido consignado um papel especial aos professores, que continuam a ser vistos como agentes efetivos de mudança, deles 
dependendo, em grande parte, tanto as transformações que urge imprimir na escola e no ensino, quanto o sucesso educativo dos estudantes e a sua realização como pessoas. (2011, p. 795 - grifo nosso)

Para ocorrer esse processo de mudança, é necessária a constante formação do professor, o que vem acontecendo dentro do grupo de Formação do Projeto Integrar chamado "Célula (de)formação", o qual está em constante debate a respeito da proposta metodológica da educação popular, proporcionando encontros de formação para a equipe de professores do Projeto, a fim de que a formação continuada seja uma realidade e que possamos avançar na prática docente transformadora. Sem a formação e o embate das ideias, a educação e os educadores tendem ao simples treinamento de habilidades práticas, ou seja, a aplicação de conteúdos, sem a devida reflexão crítica.

Segundo Contreras (2002, p. 79) "as associações de professores [em sua] organização, desenvolvem sua profissionalidade na medida em que compartilham problemas, discutem princípios, contrastam alternativas e soluções, analisam fatores que condicionam seu trabalho, organizam sua ação" - o que tem sido feito no Projeto Integrar por meio dos encontros formativos mensais.

Com esses processos contínuos de formação, pode-se garantir um aprofundamento teórico, metodológico e conceitual acerca da prática educativa dentro da EJA (Educação de Jovens e Adultos) e, com isso, proporcionar aos novos professores uma aproximação conceitual da educação comunitária. Por meio do diagnóstico, foi possível saber que os novos professores do Projeto Integrar não tiveram uma formação inicial nos bancos universitários, na qual tivessem debatido sobre as teorias da educação de jovens e adultos, sobre as abordagens metodológicas de aproximação e desenvolvimento de conhecimento, para além da mera transmissão de informação. Desta forma, o Projeto Integrar possibilita a formação do professor iniciante, pois um dos objetivos do projeto está relacionado com a formação docente na perspectiva da educação popular e do professor intelectual transformador.

Em resposta a um questionamento, em encontro de formação com os professores do Projeto Integrar, percebeu-se a importância do projeto para os professores iniciantes, 
pois os relatos mostram a importância do Projeto nas suas formações, descrevendo a mudança de concepção do fazer pedagógico. Na resposta de um dos professores, ocorre a descrição de que "mudou muito a minha concepção de tudo", pois "o projeto permite a liberdade de experiências e o aprendizado prático das utopias educacionais" (Relatos de uma educadora do Projeto Integrar, 2014).

Outra professora descreve que "depois de tudo que estudamos na Academia, e de algumas decepções que ouvimos falar quanto à educação, o Projeto Integrar me trouxe de volta a esperança para as salas de aula, me mostrando que ainda existem aqueles que lutam pela educação - não somente pelos índices”. (Relatos de uma educadora do Projeto Integrar, 2014).

Portanto, constatou-se a importância da formação para que os educadores possam fazer uma reflexão sobre suas práticas pedagógicas e, desta forma, com a reflexão da prática, repensar e criar novas práticas, no processo de ação-reflexão-ação.

\section{Professores de geografia - a formação inicial e continuada}

Ao procurar entender o processo de formação inicial nas universidades catarinenses, na formação do professor de geografia, utilizou-se como referência a Universidade Federal de Santa Catarina (UFSC) e a Universidade do Estado de Santa Catarina (UDESC). Tendo como base, mais recentemente projetos de licenciatura como o PIBID $^{6}$, a fim de incentivar novos estudantes para a prática docente. Os estágios de observação e a prática docente são realizados apenas nos ensinos Fundamental II e ensino Médio, muitas vezes dentro do Colégio de Aplicação, como é o caso da UFSC, o que não representa necessariamente a realidade das escolas públicas ou até mesmo das escolas particulares, pois apresenta um projeto pedagógico que lhe dá as condições de trabalho necessárias para os professores realizarem um trabalho de excelência.

\footnotetext{
6 Programa Institucional de Bolsa de Iniciação à Docência - PIBID/CAPES que Concede bolsas de iniciação à docência para alunos de cursos de licenciatura e para coordenadores e supervisores responsáveis institucionalmente pelo Programa Institucional.
} 
Quanto à prática docente para a EJA (Educação de Jovens e Adultos), raramente os estudantes terão a oportunidade de acompanhar um estágio de vivência, o que tornaria mais formativo se os estudantes tivessem a oportunidade de conhecer as distintas realidades do ensino, nas distintas modalidades de ensino. A formação inicial do professor, e do professor de geografia também se enquadra nessa realidade, que fica aquém das necessidades do dia a dia da escola, com suas múltiplas realidades e contextos sociais distintos. Segundo Morgado, "esta tem sido deficitária na preparação de profissionais capazes de responder aos desafios educativos de uma sociedade que rapidamente se tornou mais complexa e exigente" (2011, p. 802).

Para Pimenta (2006, p. 20), "os currículos de formação profissional deveriam propiciar o desenvolvimento da capacidade de refletir. Para isso, tornar a prática existente (de outros profissionais e dos próprios professores) é um bom caminho a ser percorrido desde o início da formação, e não apenas ao final, como tem ocorrido com os estágios".

Pergunta-se quantos professores recém-formados têm formação para atuar na EJA? Quantos têm formação para enfrentar a nova realidade das escolas com a educação inclusiva, com as múltiplas deficiências e distúrbios de aprendizagem? Ainda para Morgado (2011, p. 802), tem-se buscado na academia a formação muito mais academicista, com a apropriação dos conteúdos pelos universitários, "sem uma efetiva integração desses saberes, ainda que o período de formação inicial englobe uma etapa de prática pedagógica".

O Projeto Integrar, como movimento social urbano, lutando no campo da educação de jovens e adultos, está aberto ao dialogo com as universidades, a fim de oportunizar aos acadêmicos de licenciatura uma vivência de prática docente com o público da EJA. Por não ser do sistema de ensino formal, ocorre uma maior dificuldade e interesse para a oferta de uma oportunidade para os acadêmicos conhecerem outras realidades, outras formas de fazer educação. Em face da necessidade de ampliar as visões de mundo dos licenciandos, acredita-se que a experiência no Integrar trará frutos para o debate acadêmico, no quesito “fazer pedagógico”, enriquecendo assim a formação inicial dos licenciados em geografia e outras áreas do conhecimento. 
No ano de 2015, o curso de história da UDESC, iniciou o estágio da prática docente no Projeto Integrar, com a participação de 3 (três) estudantes em fase de formação docente no curso de história. Já no curso de geografia, também na UDESC, em seu novo currículo, torna-se possível que os estudantes de licenciatura realizem seus estágios em espaços não formais de educação. Com estas novas possibilidades de espaços para os estágios supervisionados obrigatórios das licenciaturas, os futuros professores poderão conhecer uma outra realidade de sala de aula, que não é a da educação básica regular do ensino fundamental e médio.

O Projeto Integrar, além de estar preocupado em oportunizar a experiência da prática docente para o professor iniciante, também se preocupa com a formação continuada do seu quadro de professores, pois é a formação continuada que projeta o projeto para as mudanças que a sociedade vem enfrentando nos últimos anos e, por conseguinte, os professores em sala de aula. "Proceder de outra maneira é negar aos educadores a chance de assumirem o papel de intelectuais transformadores" (GIROUX, 1997, p. 163).

Para a realidade da maioria dos nossos professores que não tiveram na formação inicial contato com os pressupostos teórico-metodológicos da EJA, torna-se essencial na formação continuada um processo de debate teórico e metodológico acerca da prática docente, a fim de garantirmos nas aulas um diálogo com os trabalhadores estudantes - e, assim, alcançar os objetivos do Projeto Integrar: transformar essas realidades.

Nas palavras de Morgado a “formação continuada é um contributo educativo valioso para compaginar pensamento e ação, reformular e atualizar a preparação dos professores, questionar as práticas de ensino, identificar problemas [...]” (2011, p. 803 grifo nosso). Na formação, tem-se buscado por meio da prática reflexiva atualizar e preparar os docentes para atuar na sala de aula com os trabalhadores estudantes, com novas metodologias de ensino, principalmente a partir do reconhecimento dos saberes prévios dos estudantes, diagnosticando em sua trajetória de vida elementos facilitadores da aprendizagem. 
Desta forma o professor reflexivo "age e toma decisões com base na avaliação dos problemas que surgem no decorrer do seu trabalho em sala de aula. Ao refletir sobre sua prática, o professor desenvolve uma atividade investigativa que contribuirá para que ele repense sua própria ação" (MARTINS, 2004, p. 51).

Com esse processo de formação continuada, alcançaram-se resultados satisfatórios, com os índices de aprovação dos estudantes nas universidades públicas (UFSC, UDESC, IFSC ${ }^{7}$ ), e também a consolidação da equipe de educadores ${ }^{8}$ que dá continuidade ao trabalho dentro do projeto.

Outro avanço conquistado foi com relação ao papel do professor, passando de um mero fazer pedagógico, ou seja, transmissor das teorias acadêmicas apreendidas na formação inicial., para um professor reflexivo (GIROUX, 1997), para um professor que pensa e compartilha no debate as múltiplas formas do fazer pedagógico. Assim “os professores podem ser vistos não simplesmente como operadores profissionalmente preparados para efetivamente atingirem quaisquer metas a eles apresentadas" (GIROUX, 1997, p. 161).

Portanto

A prática reflexiva, enquanto prática social, só pode se realizar em coletivos, o que leva à necessidade de transformar as escolas em comunidades de aprendizagem nas quais os professores se apoiem e se estimulem mutuamente. Esse compromisso tem importante valor estratégico para se criar as condições que permitem a mudança institucional e social. (PIMENTA, 2006, p. 26)

Conforme Tardif, “deveremos admitir que a prática [do professor] não é somente um espaço de aplicação de saberes provenientes da teoria, mas também um espaço de produção de saberes específicos oriundos dessa mesma prática" (2011, p. 234). Isto

\footnotetext{
7 Ver quadro de aprovações dos estudantes do Projeto Integrar nas universidades públicas catarinenses: Disponível em: http://www.projetointegrar.org/historico-de-aprovacoes/, acesso em 20 junho 2014.

${ }^{8}$ Ver equipe de educadores do Projeto Integrar: Disponível em:http://www.projetointegrar.org/conheca-otime-de-educadores-do-integrar/, acesso em 18 de abril 2015.
} 
significa dizer que os professores também são os construtores dos conhecimentos acerca da nossa prática educativa diária, ainda mais em um projeto social, o qual possui liberdade na ação metodológica para criar práticas inovadoras que venham ao encontro do processo de aprendizagem dos trabalhadores estudantes. Assim, nessa "perspectiva equivale a fazer o professor [... ] um sujeito do conhecimento, um ator que desenvolve e possui sempre teorias, conhecimentos e saberes de sua própria ação" (TARDIF, 2002, p. 234-235).

\section{Professores de geografia - o desafio da prática docente voltada aos trabalhadores da EJA}

Como estratégia metodológica, o desafio da prática docente do professor de geografia está em trazer os saberes dos trabalhadores estudantes, que têm uma vivência no mundo do trabalho, e desta forma, podem contribuir com o debate e construção do conhecimento em sala de aula. Entende-se que compartilhar as vozes dos estudantes faz com que os mesmos participem mais das aulas e se apropriem mais dos conhecimentos, desenvolvendo assim suas habilidades, que estão expressas nas palavras de Giroux (1997, p. 201-202):

compreender a voz dos estudantes significa enfrentar a necessidade de dar vida ao domínio dos símbolos, linguagem e gestos. A voz do estudante é um desejo, nascido da biografia pessoal e histórica sedimentada; é a necessidade de construirmos e afirmarmo-nos dentro de uma linguagem que seja capaz de reconstruir a vida privatizada e investi-la de significado, e também validar e confirmar nossa presença vivida no mundo. Daí decorre que silenciar a voz do estudante é torná-lo impotente.

Dialogar com os estudantes, é uma das estratégias que minimiza o que traz Cavalcante, que os professores de geografia estão enfrentando dificuldades em atrair seus alunos nas aulas, "pois a maioria não se interessa pelos conteúdos que essa disciplina trabalha" (2010, p. 3). E acrescenta que os estudantes apenas ficam limitados 
"ao cumprimento formal das obrigações escolares". Para romper com essa realidade, cada disciplina, deve ter como objetivo traduzir os conceitos, os símbolos e códigos, a fim de que os estudantes possam fazer relações com seu cotidiano do mundo do trabalho, e com isso, se apropriar dos conteúdos.

No Projeto Integrar, acredita-se que tais habilidades devem ser desenvolvidas acompanhadas de uma formação completa do sujeito, "coloca-se em foco o sujeito trabalhador, considerando as suas múltiplas dimensões e o desenvolvimento da sua consciência crítica, considerando a possibilidade de um novo patamar de inserção no mundo do trabalho" (MIYASHIRO, 2005, p. 35). Propõe-se, assim, a construção de mecanismos participativos que transformem e ressignifiquem a realidade dos estudantes.

A partir da compreensão desses processos, podem-se ativar mecanismos para uma intervenção e/ou disputa na configuração do espaço geográfico no seu lugar de vivência, dentro da escala mesolocal (SOUZA, 2013). Por exemplo, a participação das comunidades nas audiências públicas da formulação do Plano Diretor participativo da Cidade de Florianópolis/SC, ou a luta pelo direito ao meio passe estudantil para estudantes de cursos comunitários. Esse processo envolve os estudantes e faz com que os eles possam ver na prática a aplicação dos conteúdos trabalhados, fazendo sentido no seu cotidiano.

Essa compreensão/ação de ensinar a geografia é um movimento que vem sendo desenvolvido por muitos educadores na perspectiva de romper com as velhas práticas de ensino aprendizagem de geografia. Como afirma Borges Neto (2008, p. 45) em sua dissertação de mestrado na UFU (Universidade Federal de Uberlândia), “a decisão de ensinar a Geografia relacionando conteúdo e realidade pode representar uma oportunidade de renovação nos processos de ensino e aprendizagem". Por isso, propõese para o ensino de geografia a realidade trazida a partir dos conhecimentos prévios que os estudantes da EJA apresentam, para que sirvam de ponto de partida para o debate dos conteúdos geográficos programáticos.

Martins corrobora com essa perspectiva quando afirma que a formação dos professores "tem que estar voltada à organização de atividades que envolvam os alunos em projetos de pesquisas sobre a realidade escolar [...]" (MARTINS, 2013, p 154, grifo 
nosso). É imprescindível compreender essa realidade escolar, ou seja, o perfil dos estudantes da EJA (neste caso), a comunidade/lugar em que a escola se encontra, a situação socioeconômica dos estudantes/comunidade, as condições de acesso às políticas públicas conforme descrito acima, na análise da configuração do perfil dos estudantes do projeto. São formas de fazer com que os conteúdos de geografia se aproximem do mundo real dos estudantes, e com isso fazer sentido o processo de aprendizagem, buscando garantir a apropriação dos mesmos, pois “de alguma maneira, consciente ou inconscientemente, o trabalho do professor está ligado a um projeto de formação, a um projeto de sociedade, a um projeto de humanidade" (CAVALCANTI, 2010, p. 2). Busca-se assim, um projeto de formação crítica que visa uma sociedade igualitária coletiva, em que se possa viver e compartilhar os bens comuns.

Quando os estudantes conseguem se apropriar dos conteúdos e refletir sobre as práticas vividas no espaço geográfico, acontece o avanço na construção de conhecimentos e de um projeto de formação transformador. Com os conceitos geográficos apropriados, a visão de mundo do estudante se amplia, pois ele consegue fazer as relações e compreender os interesses (políticos, econômicos) ligados na transformação do espaço geográfico. Consegue compreender os processos de segregação que ocorrem nos centros urbanos da sua cidade, as desigualdades de acesso aos que vivem em situação de vulnerabilidade social, pois "na escola, pode-se dar início ao processo de compreensão da importância do mundo na vida do lugar, e deste lugar no mundo" (CALLAI, 1999, p. 6), ou seja, busca ajudar os estudantes a lerem o mundo atual, a fim de que possam construir outros mundos possíveis a partir dos novos conceitos geográficos estudados/apropriados.

Cavalcanti (2010, p. 3), defende o caminho de estudar geografia "com base no debate de temas relevantes e no confronto de percepções, de vivências, de análises, buscando um sentido real dos conteúdos estudados para os alunos". Desta forma, para o professor de geografia dar conta e estar preparado para a prática didática, além da formação dos referenciais teóricos e metodológicos da sua ciência, deve estar atualizado, atento aos acontecimentos que o mundo globalizado provoca na ordenação, na transformação do espaço geográfico, pois “hoje, na chamada pós-modernidade, a escola 
deve proporcionar os caminhos necessários para que os sujeitos/alunos possam compreender o cotidiano, desenvolvendo e aplicando competências" (CASTROGIOVANNI, 2007, p. 44).

De acordo com Kaercher “o papel do professor é destacar e aproximar o próximo, o local do aluno. Senão o mesmo acha que a geografia não lhe diz respeito por que sua aldeia não aparece na aula e nem no livro" (2003, p. 26-27). E Cavalcanti (2010, p. 6), relata que "não se trata de trabalhar o lugar apenas como uma referência local, mas como uma escala de análise necessária para se compreender os fenômenos que acontecem no mundo, mas ocorrem temporal e territorialmente nesse local”. Ao buscar nos estudantes uma formação crítica, a partir dos estudos dos conteúdos de geografia, para o exercício da cidadania, teremos assim,

um aluno que sabe compreender a realidade em que vive, que consegue perceber que o espaço é construído, e que nesse processo de produção do espaço local e do espaço regional consegue perceber que todos os homens, que a sociedade é responsável por esse espaço, conseguirá estudar questões e espaços mais distantes e compreender, indo além do aprender porque o professor quer. Ao construir seu conhecimento estará aproveitando os conteúdos de geografia para a sua formação, para ser um cidadão no sentido pleno da palavra. (CALLAl, 1999, p. 58)

Ao garantir a formação desse cidadão no sentido pleno da palavra, o objetivo do ensinar geografia, formar cidadãos autônomos e sujeitos históricos construtores da sua própria história, serão alcançados. Com isso, a prática docente do professor de geografia consegue garantir através do diálogo com os estudantes trabalhadores uma maior aproximação dos sujeitos para a aprendizagem - e, por conseguinte, as transformações da realidade, através das novas visões de mundo por parte dos estudantes trabalhadores.

Como defende Tardif (2002), que os professores passam a ser considerados sujeitos históricos do conhecimento, pois dispõem de saberes, de experiências práticas e de um ponto de vista particular, o próprio ponto de vista. Escrever e teorizar a prática pedagógica revive e fortalece a caminhada na luta por uma outra educação possível na sociedade. 
Destaca-se o depoimento da estudante do Projeto Integrar em 2014, aprovada no vestibular no curso de Medicina Veterinária nas universidades: UDESC e na UFSC. Segundo ela

Em um mundo mercenário e egocêntrico de cursinhos pré-vestibulares que custam uma fortuna e sequer sabem o seu nome, eis que surge uma flor no asfalto chamada Projeto Integrar. Gostaria de ser objetiva, mas definir o projeto seria limitá-lo, pois ele é muito mais do que um curso pré-vestibular comunitário diferenciado. O Projeto de Educação Comunitária INTEGRAR muda seu olhar pra o outro, para o mundo, Ele te transforma de dentro para fora e NENHUM ser humano sai do Integrar da mesma forma que entrou. Tenho MUITO orgulho de ter feito parte desse projeto, sou MUITO grata por toda a ajuda que recebi, tanto nos estudos como psicológica, carinho, atenção, uma relação olho no olho que jamais vou esquecer. Obrigada Integrar por me ajudar a alcançar o meu sonho. Obrigada por essa linda homenagem. Obrigada por terem reorganizado todas as peças dentro de mim e me remontarem um ser humano muito melhor. Pode ter certeza que levarei essa semente do bem pelo bem, sem esperar em troca nada que não sejam sonhos conquistados e ajuda na continuação da transformação social. Podem ter certeza que um dia eu volto para retribuir. Enquanto isso espalharei por onde eu for o poder da união de forças, a briga pelos direitos de todos, solidariedade e luta por um mundo mais justo e INTEGRADO. (LOPES, $2014^{9}$ )

No percurso formativo ao longo do ano de 2014 no Projeto Integrar, os trabalhadores estudantes puderam se apropriar dos conteúdos programáticos, a fim de conseguir passar nos processos seletivos dos vestibulares das universidades públicas de Santa Catarina, e para além dos conteúdos compreendidos e utilizados para a aprovação, conseguiram sair com uma formação política, de engajamento nas lutas sociais, se somando aos educadores do Projeto Integrar, na luta pelo acesso e na conquista de mais direitos para todos e todas.

Isso só é possível quando no processo de formação dos educadores a formação continuada garanta uma ação - reflexão - nova ação, por meio de práticas pedagógicas dialogando com as múltiplas realidades dos trabalhadores estudantes, com conteúdos

\footnotetext{
9 Depoimento da estudante Natália Lopes nas redes sociais do Projeto de Educação Comunitária Integrar,
} dezembro 2014. 
programáticos que fazem sentido no seu cotidiano, contribuindo nos avanços de uma educação emancipatória e libertadora.

A pedagogia crítica, com práticas emancipatórias considera "as particularidades históricas e sociais das experiências dos estudantes como ponto de partida para o desenvolvimento de uma pedagogia escolar crítica; isto é, ela partiria das experiências populares para torná-las significativas a fim de engajá-las criticamente" (GIROUX, 1997, p. 220).

Com uma proposta de educação emancipatória e libertadora, o Projeto de Educação Comunitária Integrar tem conseguido formar, não apenas trabalhadores estudantes para o acesso às universidades, mas também educadores em processo de formação inicial com um viés para atuar na Educação de Jovens e Adultos, compreendendo e transformando as realidades impostas pelas desigualdades sociais a esse público em específico, e ajudando a construir a luta para a ampliação e garantia de direitos para os sujeitos da EJA.

O Projeto de Educação Comunitária Integrar busca garantir a todos os educandos bases para torná-los sujeitos sociais e protagonistas de uma cidadania participativa que inclua a autonomia e o protagonismo de suas histórias. Aprendizagens que contribuam na construção de saberes com potencialidade de transformar estes jovens e adultos em sujeitos críticos capazes de transformar as suas realidades. Bem como educadores populares que possam ser atores sociais transformadores das realidades sociais dos educandos jovens e adultos. Assim, o Projeto Integrar, soma esforços para oportunizar a experiência e a reflexão da prática pedagógica na EJA para graduandos e graduandas das licenciaturas em Florianópolis/SC.

\section{Referências}

BORGES NETO, Fernanda. A geografia escolar do aluno EJA : caminhos para uma prática de ensino. 2008. 166 f . Dissertação (mestrado) - Universidade Federal de Uberlândia, Programa de Pós-Graduação em Geografia. 
BRANDÃO, Carlos R. A pesquisa participante e a participação da pesquisa. In: STRECK, Danilo R. (Org.) Pesquisa participante: a partilha do saber. São Paulo: Ideias e Letras, 2006, p. 21-54.

CALLAI, Helena Copetti. O Ensino da geografia: recortes espaciais para análise. In: CASTROGIOVANNI, Antonio (Org). Geografia em sala de aula: práticas e reflexões. 2. ed. Porto Alegre: AGB - Seção Porto Alegre, 1999.

CASTROGIOVANNI, Antonio C. Para entender a necessidade de práticas prazerosas no ensino de geografia na pós-modernidade. In: CASTROGIOVANNI, A.C (Org). Geografia: práticas pedagógicas para o ensino médio. Porto Alegre: Artmed, 2007.

CAVALCANTI, Lana. A geografia e a realidade escolar contemporânea: avanços, caminhos e alternativas. In: SEMINÁRIO NACIONAL: CURRÍCULO EM MOVIMENTO Perspectivas atuais, I, Belo Horizonte, nov. 2010. Anais do Seminário. Belo Horizonte: MEC, 2010.

CONTRERAS, José. Autonomia de professores. São Paulo: Cortez, 2002.

FREIRE, P. Educação como prática da liberdade. 26. ed. São Paulo: Paz e Terra, 2005.

FURTADO, Olinto José Varela (Pres.) et al.. Proposta de programa de ações afirmativas para ampliação do acesso à Universidade Federal de Santa Catarina com diversidade socioeconômica e étnico-racial. Florianópolis: Comissão de Acesso e Diversidade Socioeconômica e Étnico-racial, 2006.

GIROUX, Henry A. Os professores como intelectuais: rumo a uma pedagogia crítica da aprendizagem. Porto Alegre: Artes Médicas, 1997.

HENRIQUE, Wendel. A recente metropolização em Santa Catarina: processo geográficoterritorial ou apenas um limite político-administrativo? GeoTextos, v. 3, n. 1 e 2, p. 47-65, 2007.

IDEB - Índice de Desenvolvimento da Educação Básica. Brasília: INEP, 2011. Disponível em: <http://ideb.inep.gov.br/resultado/>. Acesso em: 20 junho 2014.

INTEGRAR Projeto de Educação Comunitária: professores. Florianópolis: IEE, 2014. Disponível em: <http://www.projetointegrar.org/conheca-o-time-de-educadores-do-integrar/>. Acesso em: agosto 2014.

KAERCHER, Nestor André. Geografizando o jornal e outros cotidianos: práticas em Geografia para além do livro didático. In: CASTROGIOVANNI, A.C. (Org.). Ensino de Geografia: práticas e textualizações no cotidiano. Porto Alegre: Mediação, 2003. 
LAFFIN, Maria Hermínia Lage Fernandes. A construção da docência na educação de jovens e adultos. Currículo sem Fronteiras, v.12, n.1, p. 210-228, jan./abr. 2012.

MARTINS, Rosa E. M. W. Reflexões sobre o processo formativo do professor de geografia. In: CASTROGIOVANNI, A. C; KAERCHER, N. A; TONINI, I. M. (Orgs). Movimentos no ensinar geografia. Porto Alegre: Imprensa Livre: Compasso Lugar-Cultura, 2013.

MARTINS, Rosa E. M. W. O ensino da geografia em questão: um olhar sobre o ensino médio. 2004. 119 f. Dissertação (Mestrado em Educação) - Universidade de Passo Fundo, Faculdade de Educação. Passo Fundo, 2004.

MIYASHIRO, Rosana; MORETTO, Nivaldo R. Escola de turismo e hotelaria canto da ilha - CUT, Educação Integral dos Trabalhadores: projeto político pedagógico na área de turismo e hospitalidade. Florianópolis: CUT, 2005.

MORGADO, José Carlos. Identidade e profissionalidade docente: sentidos e (im) possibilidades. Ensaio: Aval. Pol. Públ. Educ., v. 19, n. 73, p.793-812, dez., 2011.

PIMENTA, Selma Garrido. Professor reflexivo: construindo uma crítica. IN: PIMENTA, Selma Garrido; GHEDIN, Evandro. Professor reflexivo no Brasil: gênese e crítica de um conceito. 4. ed. São Paulo: Cortez, 2006.

ROCHA, Kleicer Cardoso. Formação sobre Educação Popular. IN: INTEGRAR, Projeto de Educação Comunitária. Ata da Assembleia Geral Ordinária nº 008/2015. Projeto Integrar: Florianópolis, 2015.

SOUZA, Marcelo Lopes. Os conceitos fundamentais da pesquisa sócio espacial. Rio de Janeiro: Bertrand Brasil, 2013.

TARDIF, Maurice. Saberes docentes e formação profissional. 3. ed. Petrópolis: Vozes, 2002. 